\title{
GROSSE, Rolf, Saint-Denis zwischen Adel und König. Die Zeit vor Suger (1053-1122)
}

\section{Charles Mériaux}

\section{OpenEdition}

\section{Journals}

Édition électronique

URL : http://journals.openedition.org/ifha/978

DOI : $10.4000 /$ ifha. 978

ISSN : 2198-8943

Éditeur

IFRA - Institut franco-allemand (sciences historiques et sociales)

Référence électronique

Charles Mériaux, « GROSSE, Rolf, Saint-Denis zwischen Adel und König. Die Zeit vor Suger (1053-1122)», Revue de l'IFHA [En ligne], Date de recension, mis en ligne le 01 janvier 2004, consulté le 22 septembre 2020. URL : http://journals.openedition.org/ifha/978 ; DOI : https://doi.org/10.4000/ifha.978

Ce document a été généré automatiquement le 22 septembre 2020

(CIFHA 


\title{
GROSSE, Rolf, Saint-Denis zwischen Adel und König. Die Zeit vor Suger (1053-1122)
}

\author{
Charles Mériaux
}

1 Présentée à l'Université de Heidelberg en 2001, la thèse d'habilitation de R.G. est le fruit d'une étroite familiarité avec les archives de l'abbaye royale de Saint-Denis. En 1998, l'auteur a ainsi mené à bien la publication du volume de la collection des Papsturkunden in Frankreich consacré aux privilèges des papes pour le monastère jusqu'à la fin du XIIe s. L'érudition est ici mise au service d'un projet que résume clairement le titre : présenter l'abbaye - en fait davantage son domaine, sa production intellectuelle et idéologique, la protection dont elle a joui de la part des puissances ecclésiastiques et séculières que la vie conventuelle à proprement parler - dont hérite Suger ( †1151) en 1122 et, partant, réévaluer le rôle de ses prédécesseurs, en particulier Ivo $(1072 ? \dagger 1093 / 1094)$ et Adam $(1098 / 1099 \dagger 1222)$. L'entreprise avait peu attiré les historiens. Les sources sont lacunaires et encore en partie inédites. Mais il fallait aussi prendre en compte la personnalité même de Suger, sa proximité avec Louis VII, le rôle qu'il avait joué lors de l'absence du roi, son activité administrative et - surtout - le fait que le célèbre abbé avait, en laissant une abondante œuvre littéraire, lui-même dessiné les traits que la postérité a retenus de lui. L'historiographie a donc logiquement perçu le XIe et le début du XIIe s. comme une période de difficultés, de moindre rayonnement, marquée par une indifférence des premiers Capétiens pour cet établissement dont la fortune avait pourtant été si grande entre le VIIe et le IXe s. Certains faits avaient pu être relevés - ainsi la fondation de l'anniversaire de la mort de Dagobert par l'abbé Adam - mais toujours comme signes annonciateurs de ce qui fut ensuite la politique de Suger. Le plan adopté est strictement chronologique et suit les règnes successifs d'Henri Ier, de Philippe Ier et de Louis VI. L'auteur rappelle ainsi que Saint-Denis fut bien dans un premier temps l'objet de l'intérêt de l'aristocratie locale - en particulier des comtes de Vexin - au début du XIe s. et n'attira l'attention des premiers Capétiens qu'à partir de Philippe Ier, dont les premières années du règne furent décisives, même si, comme chacun sait, c'est à Saint-Benoît-sur-Loire que le souverain demanda à être 
inhumé. L'intérêt de son fils n'a pas faibli : R.G. montre que sous l'abbatiat d'Adam et celui d'Ivo, des relations étroites sont nouées entre Saint-Denis et la cour. La première Historia regum Francorum a été composée peu après 1108. R.G. apporte en outre toute une série d'arguments montrant que le rôle de Saint-Denis dans la " consolidation de la puissance royale » (p. 231) est une réalité dans les deux premières décennies du XIIe $\mathrm{s}$. L'auteur propose en définitive une véritable démonstration et celle-ci est étayée par la présentation d'une série de dossiers d'une érudition très fouillée. Que peut-on espérer de plus ? Que R.G. applique à l'abbatiat du grand Suger la science dont il a gratifié ses prédécesseurs ? C'est chose en partie faite avec la publication récente d'un volume intitulé Suger en question. Regards croisés sur Saint-Denis (München : Oldenbourg, 2004), rassemblant les actes d'une table ronde organisée par l'auteur à l'Institut historique allemand de Paris à l'automne 2002.

Charles MÉRIAUX (Université de Reims) 